\title{
EFFECT OF KNOWLEDGE GAIN ON SPECIES CONSERVATION STATUS
}

\author{
DAVID L. ROBERTS \\ Royal Botanic Gardens, Kew, Richmond, Surrey, TW9 3AB, U.K. \\ d.roberts@kew.org
}

KEYWORDS: conservation assessment, data accumulation, knowledge, prioritisation, species discovery

\section{Introduction}

Following the 2002 World Summit in Johannesburg, the Convention of Biological Diversity (CBD) called for a decrease in the rate of biodiversity loss by 2010 (www.biodiv.org/2010-target). However, a 2003 UK Royal Society report on "Measuring Biodiversity for Conservation" discussed the lack of satisfactory measures of biodiversity, and the difficulty in accurately reporting the loss of biodiversity by 2010 . Even more pressing is the need to obtain reliable measures of extinction risk in order to prioritise proposals to reduce the rate of biodiversity loss. The World Conservation Union (IUCN) defined a set of categories for conservation status supported by decision rules for assigning species to these categories (IUCN 2001). These rules have received international acceptance and have become one of the most important set of tools for making decisions in conservation biology. However, assigning species to one of these categories often requires large amounts of data and extensive fieldwork. For most species these data are not available, and are not easily obtained; often the only available data are a "handful" of sighting records, both from the field and as records in specimen-based collections (Solow \& Roberts 2003). This is related to the level of uncertainty involved and applies to the prediction of future events, to physical measurements already made, or to the unknown.

It is estimated that there are around 2.5 billion specimens in biological collections. However, the potential contribution of natural history collections has gone largely unnoticed by the public and policymakers (Suarez \& Tsutsui 2004). These records provide information on the distribution of taxa through time and space, and represent primary, ver- ifiable observations. The value of this information is growing with the demand for rapid and inexpensive conservation assessments (Shaffer et al. 1998, Willis et al. 2003). In addition, demand is also growing for the data to be provided over the internet (e.g. www.gbif.org) as part of the CBD's policy of open access and benefit sharing.

There is therefore a need for the development of statistically rigorous methods for the production of conservation assessments from limited data, particularly those found in biological collections. Several methods have been developed which provide a probabilistic basis for an extinction hypothesis based on such sighting records (Solow 1993a, 1993b, Roberts \& Solow 2003, Solow \& Roberts 2003, 2006; McInerny et al. 2006, Solow 2006, Solow et al. 2006a, 2006b). These methods depend on sighting records of a species arranged as an order statistic $\left(t_{1}<t_{2}<\ldots<t_{n}\right)$ within some time period, $T$. To make use of these methods it is necessary to have an understanding of the collection process itself. Therefore, any attempt to use biological collections to draw inferences about species conservation needs an understanding of the collection process itself (McInerny et al. 2006, Solow \& Roberts 2006, Roberts \& Solow submitted). Care must therefore be taken to avoid bias due to sampling effects when inferring the conservation status of a species. This bias can vary considerably between taxa and geographical regions, one such form of bias is through access to specimens because of CITES (Convention on International Trade in Endangered Species). For example, to meet the 2010 target conservation assessments are required, one possible method is to assess those species that collectively best represent global 
diversity patterns. The family pairing of the Orchidaceae and Gramineae has been show to have the highest correlation coefficient with global genetic diversity $\left(r_{S}=0.973\right)$ (Nic Lughahda et al. 2005). However, given the bias, resulting from CITES regulations, on the accumulation and movement of Orchidaceae specimens (Roberts \& Solow submitted), this may not be possible. Although CITES has enjoyed undeniable success, a longstanding concern in scientific circles, which has now been confirmed (see Roberts \& Solow submitted), has been that CITES impedes the cross-border movement of scientific specimens. This concern is heightened as other international efforts to conserve biological diversity move forward i.e. Convention on Biological Diversity's and its implications for access and benefit sharing.

Another form of sampling bias can occur when comparing the distributions of two or more species based on collections containing different numbers of individuals. The relative paucity of specimens of some taxa may be related to the lag between the time of discovery and the time it takes for specimens to accumulate in collections. If sampling effort is consistently lower for recently identified taxa, there will be a tendency to underestimate key conservation parameters such as size ranges (Solow \& Roberts 2006).

\section{An Example}

Solow and Roberts (2006) compared the number of locations two species of Phragmipedium from Ecuador are found at based on herbarium specimens. P. longifolium (Warsz. ex Rchb.f.) Rolfe has a wider distribution with 8 localities compared to $P$. hirtzii Dodson with 6 . However, the distributions are based on a total of 18 specimens for $P$. longifolium whereas only 10 for $P$. hirtzii. This difference may be related to the fact that $P$. longifolium was described in 1852 , 136 years before $P$. hirtzii which was only described in 1988. This means that there has been 136 more years to accumulate data on $P$. longifolium, such as the distribution, or rather a 136 year difference in sampling effort. If the sampling effort were the same, the expected number of locations for $P$. longifolium would be around 5.3 rather than 8 .

\section{Discussion}

These considerations beg the larger questions as to why taxa are discovered when they are? And whether conservation and biodiversity prioritisation reflect a level of conspicuousness and accumulation of knowledge? Perhaps even more importantly for conservation biology is whether what we are recording is even representative of the underlying biodiversity? For instance do human tend to find large species more frequent than small species? Or do we see red-flowered species then say white? Answering these questions is particularly important given the time and money currently being spent on 'rapid biodiversity assessment'. Apart from a few papers on conspicuousness (Gaston \& Blackburn 1994, Gaston et al. 1995a, 1995b, Allsop 1997, Collen et al. 2004), there has been very little work in these areas, and even less on the link between this area of research and conservation assessments.

\section{LiteratuRE CITED}

Allsop, P.G. 1997. Probability of describing an Australian Scarab beetle: influence of body size and distribution. J. Biogeogr. 24: 717-724.

Collen, B., A. Purvis \& J.L. Gittleman. 2004. Biological correlates of description date in carnivores and primates. Global Ecol. Biogeogr. 13: 459-467.

Gaston, K.J. \& T.M. Blackburn. 1994. Are newly described bird species small bodied? Biodiversity Letter 2: $16-20$.

Gaston, K.J., T.M. Blackburn \& N. Loder. 1995a. Which species are described first? The case of North American butterflies. Biodivers. Conserv. 4: 119-127.

Gaston, K.J., M.J. Scobe \& A. Crook. 1995b. Patterns in species are description: a case study using the Geometridae (Lepidoptera). Biol. J. Linn. Soc. 555: 225-237.

IUCN (2001) Red List Categories and Criteria Version 3.1. IUCN Species Survival Commission, Gland, Switzerland.

McInerny, G.J., D.L. Roberts, A.J. Davy \& P.J. Cribb. 2006. Significance of sighting rate when inferring extinction and threat. Conserv. Biol. 20: 562-567.

Nic Lughadha, E. et al. 2005. Measuring the fate of plant diversity: towards a foundation for future monitoring and opportunities for urgent action. Philos. T. Roy. Soc. B 360: 359-372.

Roberts, D.L. \& A.R. Solow. 2003. When did the Dodo become extinct? Nature 426: 245. 
Roberts, D.L. \& A.R. Solow (submitted). The effects of CITES on scientific collections. Biol. Conserv.

Royal Society. 2003. Measuring Biodiversity for Conservation. Policy Document 11/03 (www.royalsoc.ac.uk/document.asp?tip=1\&id=1365).

Shaffer, H.B., R.N. Fisher \& C. Davidson. 1998. The role of natural history collections in documenting species decline. Trends Ecol. Evol. 13: 27-30.

Solow, A.R. 1993a. Inferring extinction from sighting data. Ecology 74: 962-964.

Solow, A.R. 1993b. Inferring extinction in a declining population. J. Math. Biol. 32: 79-82.

Solow, A.R. 2005. Inferring extinction from a sighting record. Math. Biosc. 195: 47-55

Solow, A.R., A.J. Kitchener, D.L. Roberts \& J.D.S. Birks. 2006. Rediscovery of the Scottish polecat, Mustela putorius: Survival or reintroduction? Biol. Conserv.
128: 574-575.

Solow, A.R. \& D.L. Roberts. 2003. A nonparametric test for extinction based on a sighting record. Ecology 84: 1329-1332.

Solow, A.R. \& D.L. Roberts. 2006. Museum collections, species distribution, and rarefaction. Divers. Distrib. 12: 423-424.

Solow, A.R., D.L. Roberts \& K.M. Robbirt. 2006. On the Pleistocene extinctions of Alaskan mammoths and horses. P. Natl. Acad. USA 103: 7351-7353.

Suarez, A.V. \& N.D. Tsutsui. 2004. The value of museum collections for research and society. Bioscience 54: 6674.

Willis, F., J. Moat \& A. Paton. 2003. Defining a role for herbarium data in Red List assessments: a case study of Plectranthus from eastern and southern tropical Africa. Biodiver. Conserv. 12: 1537-1552.

David Roberts was educated at the Universities of Aberystwyth, Wales and Aberdeen, Scotland, where he received his doctoral on the "Reproductive Biology and Conservation of the Orchids of Mauritius". He is currently a senior scientific officer at the Royal Botanic Gardens, Kew, where he works on the orchids of West Africa, the western Indian and alternative uses of herbarium data, particularly relating to conservation. He will soon move to Harvard to take up the Sarah \& Daniel Hrdy Fellowship in Conservation Biology, where he will be conducting research into the subject of this paper and lecturing. 